\title{
The test of time
}

$\infty$

At the Rafter Radiocarbon Laboratory we bave been successfully meeting the test of time for more than 45 years.

Athol Rafter established the laboratory in 1952. Today, using Accelerator Mass Spectrometry, we carry on the tradition of excellence that Athol Rafter began.

At Rafter we understand what our clients expect: accurate dating, at competitive rates and superior turnaround times and service.

Recent work undertaken by our team of multi-disciplinary scientists includes:

- Improving methods for contamination removal in textile dating

- Refining paleodietary studies

- Improving techniques for pollen dating

- Overcoming marine shell dating problems

The Rafter Radiocarbon Laboratory has an international reputation for accurately dating a wide range of organic materials, sediments, textiles, bone, ivory, paper, wood, parchment, charcoal, shell, foraminifera and peat.

We also offer a wide range of archaeometric services that include stable isotope measurements $\left(\delta^{13} \mathrm{C}, \delta^{15} \mathrm{~N}, \delta^{18} \mathrm{O}\right)$, amino acid profiles, PIXE/PIGME, X-ray diffraction, petrology and palynology.

For accurate dating and analysis results that will stand the test of time, talk with Dr Roger Sparks at the Rafter Radiocarbon Laboratory about your next project.

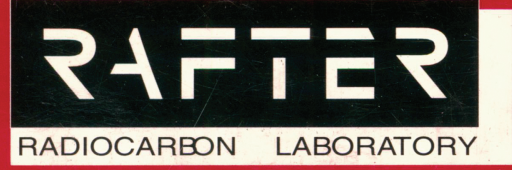

Institute of Geological \& Nuclear Sciences

30 Gracefield Road, Lower Hutt, New Zealand

Telephone: $+64-4-5704671$

Facsimile: +64-4-570 4657

Email: r.sparks@gns.cri.nz

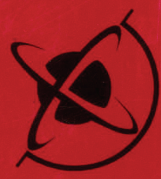

Institute of GEOLOGICAL \& NUCLEAR SCIENCES Limited 